\title{
DA SUPERIORIDADE DA LITERATURA ANGLO-AMERICANA — DELEUZE CRÍTICO LITERÁRIO?
}

Mauricio Salles Vasconcelos

$U F M G$

\section{RESUMO:}

Este ensaio analisa alguns autores americanos $e$ ingleses contemporâneos a partir da perspectiva dos conceitos de Deleuze sobre a "superioridade da literatura anglo-americana". PALAVRAS-CHAVE

Narrativa. Territorialidade. Escrita e conceito.

Uma das possíveis visões de um filósofo como Deleuze sobre a literatura, além daquela favorecida, de modo mais flagrante, por seu últímo livro editado em vida - Critique et clinique (1993), que reúne artigos inéditos e outros publicados, em sua grande maioria, sobre autores literários —, pode ser percebida em um ensaio integrante do volume Dialogues (1977), intitulado "De la supériorité de la littérature anglaise-américaine". Se o filosófo chega a lastimar, em seus últimos anos, a não realização de um estudo mais sistemático sobre a literatura, como aquele dedicado ao cinema (desdobrado nos volumes L'image-mouvement e L'image-temps), não obstante a produção de obras concentradas sobre as produções de Proust (Proust et les signes) e de Kafka (Kafka-Pour une littérature mineure, em co-autoria com Guattari), um recorte provável de seu pensamento sobre a criação literária pode ser apreendido em ensaios diretamente relacionados com o tema, caso de "Littérature et vie", constante do volume já citado de crítica (1993), e daquele de 1977, sobre o qual me deterei. 
A referência a escritores de lingua inglesa, do século XIX para cá, incorporados ao pensamento e à escrita produzidos pelo filósofo, tornada consistente desde Logique du sens (1969) - obra escrita sob o corte dos paradoxos de Lewis Carroll em igual proporção àqueles produzidos pela filosofia de Frege (centrada na lógica dos paradoxos) - , chega a alcançar em muitos dos capítulos-programas de Mille plateaux (1980) o caráter de uma viva seleção, quando estuda Henry James e Scott Fitzgerald (como já havia feito com este autor, em "Porcelana e vulcão", $22^{2}$ Série de Logique du sens, em um paralelo com Malcolm Lowry) em Trois nouvelles ou "Qu'est-ce qui s'est passé?". Uma nítida orientação de princípios criativos e estratégicos também é percebida, quando Deleuze pensa o continente americano e seus autores no capítulo introdutório dos Plateaux, dedicado ao Rizoma.

No estudo de 1977, Deleuze ressalta traços operacionais e territoriais relacionados à escrita literária, a que a introdução de Mille plateaux daria acabamento ao conceituar o rizoma, no sentido de um corte com a literatura e ao livro europeus - franceses, para ser preciso. $O$ escrever, ou, para usar seus próprios termos, "o objeto mais alto da literatura", significa o ato de "traçar uma linha (...) seguindo Lawrence":

Partir, partir, evadir-se (...) atravessar o horizonte, penetrar em uma outra vida (...) A linha de fuga é uma desterritorialização. Os franceses não sabem bem o que é isto. Evidentemente eles fogem como todo mundo, pensam que fugir é sair do mundo, mística ou arte, ou melhor que é algo covarde, pelo fato de se escapar aos compromissos e às responsabilidades. Fugir, não é renunciar às ações, nada mais ativo do que uma fuga. ${ }^{2}$

O que se percebe na ênfase às linhas de fuga é o traço de um princípio cartográfico, que contraria a tendência sistematizadora, centrada no modelo da árvore e suas raízes, no estabelecimento da origem e da reprodução, via decalque, de funções hierarquizadas no interior de um dado sistema. Opondo-se à hegemonia do estruturalismo, aos modelos-decalques de "algo que se dá já feito"s e existe apenas em função de, a partir de "uma estrutura que sobrecodifica ou de um eixo que suporta (...) os decalques são como folhas da árvore","o

1. DELEUZE, 1977. p. 47

2. Ibidem

3. DELEUZE e GUATTARI, Mil platos Vol. 1., p. 21.

4. Ibidem
Deleuze de 1977 aponta para o modelo-imagem do mapa, assim inscrevendo toda uma postura geofilosófica, reveladora do próprio trajeto de seu pensamento antes e depois da passagem por Mille plateaux. Nesse sentido, alinhar-se à desbravação geográfica inerente à constituição da literatura americana significa para o filósofo francês a ruptura - e a imagem da linha de fuga mostra-se aí possante, poética, neste contexto de crítica da literatura - com o mundo histórico, genealógico, cadastral, representado pela França dos filósofos e dos romancistas, da arborescência psicanalítico-língüístico-estrutural dos 70 , a França fantasmal da literatura do significante.

A literatura americana opera por linhas geográficas: a fuga para o Oeste, o sentido das fronteiras como algo a transpor, a reincitar, a ultrapassar. O devir é geográfico. Não há equivalente disto na França. Os franceses são muito humanos, muito históricos, muito ciosos do futuro e do passado. Passam o tempo a marcar o ponto. Não sabem do transformar-se, pensam em termos de passado e de futuro históricos. Mesmo quanto à revolução, pensam em um "futuro da revolução" em vez de um devir-revolucionário. Não sabem traçar linhas, seguir um canal. Não sabem furar, raspar o muro. Amam demais as raízes, as árvores, o cadastro, os pontos de arborescência, as propriedades. Vejase o estruturalismo: é um sistema de pontos e de posições, que opera por grandes cortes ditos significantes, em lugar de proceder por avanços e quebras, o que acaba por entulhar as linhas de fuga, em vez de segui-las, de traçá-las, de prolongá-las em um campo social. ${ }^{5}$

O que Deleuze percebe a partir de autores americanos como Melville, Stevenson, Wolfe, Fitzgerald, James, Lovecraft, Miller e Kerouac, e também de ingleses como Hardy, Lawrence e Virginia Woolf, diz respeito à capacidade de ser concebida a escrita por seus procedimentos táticos com relação à origem de ser concebida a escrita por sesta literatura, atuando através de posturas estratégicas no que se refere aos valores da terra, à idéia totalizante de nação, à representação do espaço físico. Quando opõe a fuga à viagem, Deleuze dá realce à qualidade desbravadora de uma ficção que nāo se direciona para um ponto original, da ordem do substancial, no sentido em que concebe o pensamento de Spinoza - ver p. 74 - na direção contrária a um princípio, substancia única para todos os atributos. Mas se comunica por meio do que se quebra, do ponto significativo de ruptura, que não se deixa preencher, representar, reterritorializar, de um a outro autor no mapa de linhas de fuga cartografadas pela escrita, de um a outro recomeço criativo. Para isso se utiliza de uma imagem geográfica, com

5. DELEUZE, 1977. p. 48.
REVISTA DE ESTUDOS DE LITERATURA

Belo Horizonte, v. 5 , p. 125 - 144, out. 97 
o impacto conceitual de um platô, de um verdadeiro não-lugar — de passagem estreita sobre o vazio - que desponta pelo meio:

Uma verdadeira ruptura pode eclodir no tempo, é outra coisa que um corte significante, deve, sem cessar, ser protegida não somente contra seus falsos iguais, mas também contra si mesma, e contra as reterritorializações que a espreitam. É porque de um escritor a outro, a ruptura salta como aquilo que deve ser recomeçado. Os ingleses, os americanos não têm a mesma maneira de recomeçar que os franceses (...) a busca de uma certeza primeira como de um ponto de origem, sempre o ponto fechado. A outra maneira de recomeçar, ao contrário, é retomar a linha interrompida, juntar um segmento à linha rompida, fazê-la passar entre dois rochedos, em um desfiladeiro estreito, ou por cima do vazio, aqui onde ela havia cessado. Não é jamais o começo nem o fim que são interessantes, o começo e o fim são pontos. $O$ interessante é o meio (...) Não somente a erva brota no meio das coisas, ela brota pelo meio. É o problema inglês ou americano. A erva tem sua linha de fuga, e não de enraizamento. Tem-se a erva na cabeça e não uma árvore: o que significa pensar, o que é o cerebro, "um certo sistema nervoso" (Steven Rose, $L e$ cerveau conscient, éd. du Seuil), da erva."

Quando o filósofo de Mille plateaux estuda o "caso exemplar" de Thomas Hardy, fica clara a disposição diagramática, rizomática, do mapa das linhas-de-fuga traçada no interior do moderno sistema literário anglo-americano. Hardy é destacado justamente por dispor de personagens, que não são "pessoas ou sujeitos", mas "coleções de sensações intensivas", "um bloco de sensações variáveis." Revela-se no autor de Jude The Obscure uma literatura que se faz por sondagem, pela consistência conceitual (com o reforço da concepção filosófico-religiosa de que este livro se entretece) de um produzir ficção e ação em graus sincronizados, através de produtos/constructos do pensamento, estendidos como linhas de escrita, operações táticas sobre o plano da terra, da territorialidade. ("... A frase-lande, a linha-lande de Thomas Hardy: não que a lande - que tem em português o nome de charneca, terra inculta, humosa, pântano - seja o sujeito ou a matéria do romance, mas um fluxo de escrita moderna se conjuga com um fluxo de terra (lande) imemorial", p. 62). Um

6. bidem.

7. Ibidem. p. 50-51 processo, enfim, compreendido pelo filósofo, também crítico da literatura de língua inglesa, como descartado da remissão a um eu ou lugar originários, aberto, contudo, com o não-tempo da matéria, terra mater, em contínuo contato de uma

Individuação sem sujeito. E esses compactos de sensações ao vivo, essas coleções ou combinações (...) percorrem a lande como linha de fuga, ou linha de desterritorialização da terra. ${ }^{8}$

É marcante e reincidente, no pensamento de Deleuze, a imagem, colhida na poesia de Whitman, da literatura e do livro que são uma coleção de folhas de relva, de erva, arrancadas de um sistema, de uma fundação-nação, de um corpo e de um sujeito encerrados, constituídos em identidade, em autoria literária, que se furtam à superfície, ao que está fora, ao que escapa como ramificação nervosa, rizomática, do cérebro em contato, à flor da pele, da terra. Leaves of grass, o livro feito e desfeito a cada edição pelo poeta da América, livro-fluxo incessante, é bem um emblema para Deleuze da escrita realizada à altura da terra, carregada dos traços mortais, terrenos e estratégicos no que aí se tocam os sentidos da nação, do indivíduo e de sua passagem com um corpo pelo tempo, pelos espaços da literatura, passagem por territórios. "Escrever, fazer rizoma, aumentar seu território por desterritorialização..." (Eis o mote do estudioso de literatura e produtor de escrita na fronteira de disciplinas e de uma crítica/clínica marcada como que por um ritornello da própria terra, em que pensar e criar se imbricam).

Em uma aproximação com a produção literária americana de hoje, o poema-projeto (contido na obra de Whitman) de uma busca gregária, comunitária, que se realiza sobre um território mas no sentido intensivo e inventivo de linhas/ fluxos apontados para o descentramento, e também o desterro, das idéias de eu e de nação, não deixaria de encontrar eco ou, para dizer em termos geográficos, uma passagem, estreita que seja. Ao tomar a obra contemporânea de, por exemplo, Kathy Acker para um diálogo com o pensamento deleuziano acerca da literatura moderna em língua inglesa, observo em suas narrativas a capacidade que têm de traçar conexões, de fazer cruzar linhas entre os estratos do mapa social americano e os saberes entrecortados pela literatura.

O que notava o filósofo acerca da passagem, do devir, de "salto, demônio, relação com o fora", em Melville e os outros da América, rumo à

8. lbidem. p. 51.

9. DELEUZE e GUATIARI, Mil plotos vol.1., p. 20. 
criação de uma "nova Terra"10, parece encontrar sua linha de atualização em Acker. Linha, veio, e não linhagem, seria o caso de se dizer. Uma linha de escrita e de ação aberta, talvez, pela poética de Rimbaud no terreno de uma genealogia selvagem, bárbara, inumana (em ataque eficaz ao humanismo eurocêntrico), animal, para o autor/produtor moderno. $\mathrm{O}$ poeta estrangeiro à França - à "vida de honra" bem à francesa, como diz em Une saison en enfer —, nômade (por sua viagem imóvel dentro da África, e não pelo fato de ter fugido da velha Europa, mas pela anti-epopéia, obra-vida não-modelar, pela cartografia radical, terminal, dos limites humanos e literários geograficamente dados como linha-de-fuga traçada ao ilimitado, ao impossível, ao fim do mundo), não por acaso, teve sua obra e vida reescritas pela ficcionista - e também ensaísta - americana no romance In memoriam to identity (1990).

Demon! A autora de My mother: Demonology (1993) investe suas narrativas sobre um território, que é o sistema da sexualidade explicitamente americano, no qual o corpo se instaura como peça agenciadora da escrita literária, no interior de uma ficção que é citacional, apropriativa de gêneros e títulos os mais diversificados (do Dom Quixote à cyberfiction de William Gibson, da literatura pornô aos mitos gregos), ensaística e também autobiográfica (no processo, sem dúvida, de uma individuação dada através do escrever, sem sujeito).

A imagem que conviria a Kathy Acker e à arte da narrativa, segundo ela, é a da mulher-pirata, da pirataria, enfim, entendida no sentido mais criativo, e culturalmente atuante, do termo. Não à toa, ela cultuabs e exibia (faleceu em 1997) a tatoo art sobre sua silhueta de mulher forte e produtiva como insígnia pluritextual da literatura do corpo (como, de vez, esclarece o subcapítulo "Toward a literature of the body", de My mother...) por ela praticada em todas as suas narrativas. A respeito de sua produção já foi atribuído o conceito de apropriação, que muito tem a ver com a técnica citacional/situacional do sampler, no campo da música eletrônica de agora, entendendo-se que a autora, ao desenvolver os cortes/recortes próprios aos cut-ups de Burroughs (tal como testemunha em uma entrevista dada a Sylvère Lotringer, em 1991, v. Bibliografia), chega a incluir, em bruto, textos inteiros dos escritores mais variados no espaço de suas narrativas. Ao ponto de causar problemas a seu editor ante um processo de plágio passível de ser movido por Harold Robbins, o clássico escritor de best-sellers, que teve trechos contínuos de seu The pirate inseridos, por obra da pirataria de Kathy Acker, no contexto, também apropriador, do romance The adult life of Toulouse-Lautrec, de 1975. Mas a pirataria tem seu começo a contar dos materiais subjetivos trabalhados pela ficcionista.

10. DELEULE, 1977. p. 48.
Por sua postura combativa, pelo foco dado, em entrevistas, ensaios e em sua produção narrativa, ao debate sobre o corpo e o lugar do desejo no contexto do pós-feminismo (e do pós-modernismo), assim como pela inserção abrangente, sempre constante, de tal debate na conjuntura da vida, da nação americana, Kathy Acker conduz aos circuitos de uma "potência não pessoal" o arsenal claramente biográfico de sua ficção, com todas as reincidências conflitivas, irresolvidas, centradas na infância, na vivência familiar, nos códigos masculinos, tipicamente nacionais, aderidos à manifestação de sua sexualidade. É o que é dito através das cartas da mulher ao amante, cartas da mãe ao pai:

Tudo o que me atormenta agora, tudo o que tem me atormentado, ao ponto que é doloroso, é que nós dissemos tudo um ao outro. Já que eu temo a rejeição mais que tudo, devo ter confiança. Não serei capaz de deixar sua vida e você não será capaz de deixar a minha. A despeito do fato de que - eu não estou perdendo meu tempo tentando explicar isso para você ou convencê-lo de que isso é verdadeiro - seu mundo é aconchegante. $\mathrm{Eu}$ — não sou nada. Eu prometo que não envergonharei você com sua presunção. Você precisa desse tipo de merda: imagens de riqueza, talvez por não termos nascido daquela maneira, então você pode viver intimamente em seu mundo. Eu preciso ficar invisível e sem linguagem, animal..$^{12}$

Em My mother: Demonology, tal como havia realizado em In memoriam to identity, a romancista produz um tipo de narrativa que, sem abdicar do relato circunstanciado de experiências encaminhadas por uma primeira pessoa, sempre feminina, sempre passional e participativa quanto aos rumos do relato, instaura em seu projeto uma direção conceitual, capaz de examinar bem de dentro, no interior da emotividade e sensibilidade femininas contidas no romanesco (não é por acaso que o modelo de sua apropriação se trata agora de Cathy em The Wuthering Heights) valores da mulher e do corpo americanos, em seus desdobramentos familiares, afetivos, políticos, sexuais. Não ficando sem abrir, está claro no trecho citado da obra, uma via, uma linha de fala projetada para a imperceptibilidade, para a animalidade, de que trata Deleuze quando aborda o devir no capítulo 10 de Mille plateaux ("Devir-intenso, devir-animal, devir-imperceptível"), mas já toda à mostra no ensaio, em estudo, de Dialogues:

\section{1. bidem. p. 61.}

12. ACXER, 1993. p. 21 
Escrever não tem outra função: ser um fluxo que se conjuga com outros fluxos - todios os devires-minoritários do mundo. Um fluxo é qualquer coisa de intensivo, de instantâneo e mutante, entre uma criação e uma destruição. ${ }^{13}$

Neste sentido, não haveria palavras de ordem, no que escreve K.A. com relação ao devir-mulher, pois seu trabalho se orienta, ao incorporar a perspectiva da mãe no romance citado, em uma redefinição do feminino, numa incursão aos seus regimes e regimentos, após o feminismo. Todo o devir é feminino, trata-se do devir minoritário da escrita, mesmo para a mulher, ${ }^{14}$ erguida pela luta de seus direitos, tal como configurada historicamente, à condição já de maioria. A sexualidade não deixa de se fazer, de se relançar e de romper-se, regida que é por fundamentos extensivos à produção cultural e material, é o que parece assinalar a produção de Acker.

O projeto de romance, de livro, para Kathy Acker está tomado pela força de uma escrita-conceito, que o torna uma produção/apropriação em série de um mesmo princípio, reatualizado (e ritualizado) a cada título, à maneira de Whitman e sua coleção de folhas experimentais, escritas e trabalhadas sobre o território da América: uma espécie de rebento/rizoma, excessivo, entremeado do caráter de um programa de vida (do modo como formula Deleuze). ${ }^{15}$ Pelo vigor de sua consistência prática e crítica, não se apresenta como simples manifesto mas como ficção disposta em vias múltiplas, por conter o traço da auto-iniciação, da aprendizagem pela escrita, sem perda da força e do intempestivo próprios de um produto híbrido, desalinhado do sistema literário dos gêneros. Escrita que traz a marca ensaística, apropriativa e experiencial, de um conceito sobre a mulher, o romance e a terra americana.

Aqui estão meus mais recentes pensamentos: Quando encontrei você eu estava me afogando porque não ia deixar mais outra pessoa ficar próxima de mim. (Essa frigidez é chamada "selvageria").

Pedi a você, melhor do que ninguém mais, por socorro pois soube que você era um paralítico emocional. Perversa, como sempre, eu gritei, "Socorro!" de maneira que você me bateu na cabeça suficientemente

\footnotetext{
13. DELEUZE, 1977. p. 60.

14. DELEUZE, 1977. p. 55.

15. Ibidem.
}

para eu me afundar ou cair de um monte em erosão. O que eu realmente queria fazer. Você é apenas o que eu quero, B: um método mais aperfeiçoado de morte.

Decidi dizer a você tudo porque dizendo tudo eu levaria você a me matar mais rápido. Eu sempre quero testar tudo até o ponto da morte. Além.

(Crianças e cachorros agachados na sujeira.

("Isso parece a alta estrada para o Inferno", disse um guri. ("Do Inferno."

(Era uma terra desolada, uma populaça que nada possuía exceto criminais do Governo, e agora estava indo para a guerra. Uma vez que ninguém sabia onde o país com o qual lutavam estava, ninguém pensou que tudo fosse real.

(O que devem ser as armas nesta guerra de imaginação - tornadaatual ninguém sabia. Esqueletos mal-enterrados de vacas, cavalos com bocas ressequidas e abertas, pernas de gatos e bodes.

\section{(EM SUAS TERRAS OS ÁRABES ARRANCARAM OS OLHOS DOS OUTROS E ESTUPRARAM SUAS PRÓPRIAS CRIANÇAS. SE ALGUM SOLDADO AMERICANO VAI PARA A BATALHA, PORQUE O DEVER ASSIM O EXIGE, ELE TEM QUE VENCER.}

- algum oficial do Governo americano ${ }^{16}$

Não há na escrita de Acker separação entre as fronteiras do público e do privado, tendo-se em vista a conexão máxima de linhas entre a letra íntima da carta, do diário, dos procedimentos menores do escrever (mostrando-se aqui bem próxima da poeta brasileira Ana Cristina César, veio forte de nossa produção contemporânea, em sua valorização das formas literárias femininas) e outras de ordem (geo)política, histórica, territorial. Linhas íntimas se conectam em um raio extenso de probabilidades, que se entrecruzam na superfície do escrito, sob um nítido rigor de montagem (proveniente, sem dúvida, dos experimentos

16. ACKER, 1993. p. 23-24.

$$
\begin{aligned}
& \text { REVISTA DE ESTUDOS DE LITERATURA } \\
& \text { Belo Horizonte, v. } 5, \text { p. } 125-144 \text {, out. } 97
\end{aligned}
$$

$1 \mathbf{3}$ 
a contar de seus próprios depoimentos, em seu encontro progressivamente significativo com a literatura.

O conceito de narrativa comparece, segundo Ross, para dar conta de um escrito em primeira pessoa, rompido com as expectativas de um romance de educação ou formação, a tudo o que conduz à formação/conformação de uma personalidade, em acordo com os ditames do mundo social. No romance, o personagem, ao final, apresenta-se como "uma figura transformada e, de modo geral, moralmente reformada." 20

É tudo o que não acontece nas obras atuais de Kathy Acker e Gordon Lish, em busca do alto objeto de uma literatura, que não tem senão os recursos conflitivos da individualidade para processar sua iniciação no tempo e no espaço precisos de um país, no caso da América de My mother: Demonology e Peru.

As linhas traçadas por estas narrativas são o contrário da viagem (e sua restituição subjetiva/espacial, ao fim do relato/romance, do narrativo como fim: educação/término da experiência), pontuam-se pela fuga, pelo desterro, do modo como comportava-se "Mauvais sang" dentro do sistema cartográfico/ geográfico vigentes, dentro e fora da Europa "falsa negra", colonialista, através de territórios desterrados, desertificados, pela mobilidade anti-ilustrativa de um corpo em ação, próprio ao sujeito multiplicado, despessoalizado, de toda a Saison (uma estação, uma temporada, que traz o sentido físico de uma incursão).

A leitura de Blanchot feita por Kristin Ross, torna mais clara a força de sua influência sobre o pensamento de Deleuze, influência exercida, por sinal, pelo grande crítico e filósofo da literatura no pensamento francês (como bem recentemente Éric Alliez acabou por confirmar em um estudo sobre a filosofia contemporânea). ${ }^{21} \mathrm{O}$ que se faz sentir em direção a uma literatura do homem desterrado/desterritorializado, esse que, tomado pela narrativa, desde Ulisses pelas sereias, não realiza o relato do acontecimento, "mas precisamente esse acontecimento, a aproximação desse acontecimento, o lugar onde este é chamado a produzir-se acontecimento, ainda por vir e graças a cujo poder de atração a narrativa pode esperar, também ela, realizar-se."22

Próximo do caminho estóico, que consiste, para o filósofo e crítico da literatura - a partir do repertório de língua inglesa -, em um tornar-se digno do acontecimento (fórmula impactante do amor fati, já explorada em
20. ROSS, p. 48.
21. AlliEZ, p. 36.
22. 8LANCHOT, p. 14 
Logique du sens, retomada aqui, à página 80), o pensamento de Blanchot é mencionado por Deleuze (em rodapé do ensaio de 1977, à mesma página) como exemplar da exploração e entrega à manifestação dos eventos, à fulguração da superficie, em que se concentrava também Spinoza. "O que pode um corpo?", pergunta spinoziana essencial ao cartografar/grafar o movimento e o devir próprios à narrativa, quando atenta ao trabalho empírico, experimental, dos afetos aflorados e em fuga, em linhas de leitura, de literatura, que não descartam a especulação, o rastro do conceito, à altura do acontecimento (esse que a mirada historicizante não dá conta e não fomenta).

A narrativa para Blanchot - e com igual força desterritorializante para Deleuze - significa o diálogo com sua lei secreta, o contato com um lugar extremo, arriscado, pois marca-se pelo

movimento para um ponto, não apenas desconhecido, ignorado, estranho, mas tal que parece não ter, antecipadamente e fora desse movimento, qualquer espécie de realidade, e tão imperioso no entanto que só ele atrai a narrativa, de modo que esta nem sequer pode "começar" antes de o ter atingido, e no entanto apenas a narrativa e o movimento imprevisível fornecem o espaço onde o ponto se torna real, poderoso e atraente..$^{23}$

É assim que o narrador de Peru, de Gordon Lish, trava contato com um lugar vacante, improvável de ser penetrado, no seio do cotidiano tipicamente classe-média, um ponto/linha de fuga desbravado desde a infância para fora dos contornos do quadrado de areia no qual brinca e se digladia com as crianças da vizinhança. Ponto impreenchível no auge da vida adulta, como uma força ainda desestabilizadora, ante o filho, ante a família, rumo ao território submerso, à região violenta, monstruosa e indesejável, representada pela outra América, para a qual o narrador e seu relato se encaminham: "Peru".

No lugar recalcado, remoto, impensável, ao narrador americano, Lish vai situar a sobreinfância, de que fala Kristin Ross quando observa nas linhas de Une saison en enfer, a "energia da transformação, de pura transição" ${ }^{24}$, rebelde ao toque conclusivo, romanesco, da educação. Em Peru, o personagem-narrador não se emancipa, deixa-se conduzir pelo movimento descêntrico que a memória (com seu esforço restituidor de um terrível acontecimento da infância) tenta apreender frente ao caos de fatos inacabados, frente à terrível selvageria de

23. Idem, p. 14-15

24. ROSS, P. 49 "coisas começando e nunca se completando, de partes delas que era impossível que você conseguisse tomar conta totalmente."25

As forças do desterro, forças desterritorializantes encontradas no terreno da literatura do país hegemônico, modelo ocidental, exibem um panorama que não é o da escrita documental, jornalística, nem da máquina best-seller de produzir ficçōes, que representam o modo mais corrente de veicular a produção diversificada de uma nação formada por muitas outras, desde suas origens, e por narradores não conformados às demarcações territoriais e aquelas que tangenciam entre a ficção (em tudo o que possui de mega, de superprodução, de espetacularização do imaginário) e o verismo imputado ao conceito de realidade. Seja em autores revelados nos anos 60 , marcantes na formação da literatura pós-modernista americana, caso de Thomas Pynchon, Robert Coover, literatura porth e Donald Barthelme, seja em outros mais contemporâneos, já representativos de uma trilha própria, trabalhada em franco diálogo com a produção européia (Kafka, Beckett), como Paul Auster, mostram-se bern nítidas as orientações cartográficas de escritos mais e mais indissociáveis do princípio de hibridização, como bem nota Marc Chénetier, em artigo dedicado a 30 anos de literatura nos Estados Unidos (“.... a simples separação entre poesia, teatro, novela e romance, ficção e não-ficção, não é mais possível, a hibridização reinando de maneira significativa nos melhores textos ...")..$^{26}$

Já haviam estudado Gilbert-Rolf e John Johnston, em um importante ensaio ${ }^{27}$, a relação entre Gravity's Rainbow (1973), de Pynchon, e a escultura ou arquitetura de paisagem - bem representativa da land-art - Spiral Jetty Star (Estrela do Quebra-Mar Espiral), projetada em um filme, projeto de autoria de Robert Smithson (1969-70). Entre as obras, entre as artes, está o cinema, que é orgânico em Pynchon - da simples menção iconográfica, hollywoodiana, que percorre sua escrita de $V$ a Vineland, até a instauração do movimento, um ritmo sonoro-visual que engendra todos seus livros - sendo dado destaques tanto a Gravity's Rainbow quanto ao anterior The crying of lot 49 - ao que tanto a Gravity's Rainbow quas da narrativa em seu sobrevôo do acontecimento (parafraseando Deleuze, ao lado de Guattari, em Qu'est-ce que la philosophie?). (parafraseando Deleuze, ar suas narrativas o lugar dado à fuga e à deambulação por territórios urbanos e por sites da natureza americana, configurados em uma dimensão aberrante (para usar um adjetivo caro a Deleuze), nada ilustrativa,

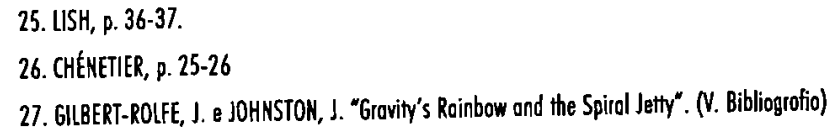

[1] 37 
do espaço físico (um trajeto que vai de $V$, livro de estréia, até Vineland, seu penúltimo romance)

Escrita-conceito a performar os textos de Pynchon, como ocorre em Acker e Lish, por vias tão diferentes, mas confluentes no sentido do mapeamento. Não à toa, Gilbert-Rolf e Johnston frisam a "a recuperação e a especificidade geográfica na ficção de Pynchon e também no filme de Spiral Jetty."

Um autor como Paul Auster, em The New York Trilogy, conjuga a sondagem de um território preciso - a big city planetária -, com os recursos de uma investigação capazes de imprimir pulsação, movimento, à autoposição, autoexposição (com o nome autoral, Paul Auster, desdobrado em cruzamentos analógicos com o modelo master moderno do duplo, o William Wilson, de Poe) da narrativa (com os procedimentos experimentais da Europa não-romanesca, não negados pelo itinerário ensaístico do autor), em seu projeto de livro-cidade sequenciado pelo ritmo da caminhada, que se traça nos labirintos novaiorquinos (apartamentos mínimos, metrôs, bares, cubículos).

Diversificadas, as experiências narrativas contemporâneas nos EUA podem partir do dado local, da contingência atraente que é escrever em New York - de decifrá-la, como faz Auster, na corrente de uma tradução barroca, criptográfica, do universo como texto e labirinto, dispersado em dobras de sentido, e de lugares no tempo e no espaço, tal como assinalado por Borges. Mas realiza-se também na vertente também de uma escrita timbrada pela leitura da poesia moderna, aquela próxima da rua, da caminhada pelos espaços urbanos e outros mais e mais deslocados até a desertificação (em uma gradação que vai de Baudelaire, Rimbaud, Whitman, Apollinaire até, mais recentemente, Jabès).

Nova York era uma cidade inegostável, um labirinto de passos sem fim. Não importa quão longe ele fosse, o quanto conhecesse da cidade, sempre lhe ocorria a sensação de estar perdido. Não apenas dentro da cidade, mas dentro de si mesmo. Toda vez que saía a caminhar, sentia-se como quem deixa a si próprio para trás, entregando-se ao movimento das ruas. Ao reduzir-se a um observador, escapava à obrigação de pensar, e isso, mais do que qualquer outra coisa, proporcionava-lhe a medida exata da paz e um salutar vazio interior (...) $O$ movimento, $o$ ato de colocar um pé adiante do outro e abandonar-se ao impulso do próprio corpo era a essência de tudo. Ao vagar sem destino, todos os lugares tornavam-se

28. Idem, p. 81. iguais, e não mais lhe importava seu paradeiro. Suas melhores caminhadas eram quando sentia estar em lugar nenhum, e isso era tudo o que queria: estar em lugar nenhum. ... Nova York era esse lugar nenhum que construíra em torno de si... ${ }^{29}$

$\mathrm{Na}$ cidade cosmopolita, a menos representativa do fundamentalismo, do localismo americanos, a narrativa abre-se para todas as pistas importantes à ação da Trilogia, assim como a todas referências culturais - Poe, o cartógrafo do urbano, das multidões, está incorporado, renomeado, desde o princípio possíveis de se obter como mapa neste ponto de passagem, para fora das margens conhecidas, no sentido de habitar, de ocupar um lugar (a refeitura, através de diagramas/mapas de caminhadas, da cidade é um fato que se instala graficamente no corpo da narrativa). O escrever, como o pensar, para Deleuze, faz-se fisica, geograficamente, lida com imagens do mundo/imagens do pensamento de forma que signifiquem posturas, atos visíveis, deambulações, trânsitos em formação, movimento (o cinema, a que Auster vem se dedicando, de modo crescente, como roteirista e realizador, outra vez comparece, como engendramento, sequienciamento, da ação de corpos sobre territórios. Até um tornar-se imperceptível aos olhos do leitor).

Mesmo no universo, cada vez menos paralelo, da science fiction, a chamada literatura virtual veio ocupar um lugar cada vez mais central. Um nome como William Gibson, que dá declaradamente sequiência às experiências de linguagem, de recorte/montagem da informação, realizadas por Burroughs - "a diferença entre o trabalho de Burroughs e o meu é que ele cola todas as coisas na página, enquanto eu faço um airbrush de tudo"30 - , principalmente na trilogia sci-fi (Nova Express; The soft machine; The ticket that exploded), produz um verdadeiro desenquadramento do lugar extra-territorial assentado pela literatura entre utópica e apocalíptica produzida no gênero. $\mathrm{O}$ arsenal tecnotrônico transforma-se nas mãos do criador de Neuromancer (1984) em peças das conexões orgânicas, corporais, tomadas pelo constructo narracionalnocional de uma outra ordem de espaço.

A admissão sensorial em Case alterava-se com a velocidade a que se deslocavam.

Sentiu a boca ser invadida por um sabor doloroso.

\section{AUSTER, P. 8.}

30. GIBSON, 1992. p. 70 
Tinha os olhos como se fossem ovos de cristal instável, a vibrarem numa freqüência cujo nome era chuva e ruído de trens e que fazia brotar uma floresta sussurrante de espinhas de vidro, da espessura de um cabelo. As espinhas separavam-se, biseccionavam-se e separavam-se de novo, num crescimento exponencial, sob a cúpula do ECI da Tessier-Ashpool

O palato, como que anestesiado, admitia a entrada de radículas que o fustigavam à volta da língua, esfomeadas de sabor de azul para alimentarem florestas de cristal dos olhos; florestas que se comprimiam contra a cúpula verde e eram impedidas de prosseguir; então, desenvolvendo-se para baixo, espalhavam-se e preenchiam o universo da T-A, os subúrbios miseráveis da cidade que era a mente da TessierAshpool.

Lembrou-se de uma história antiga, de um rei que punha moedas num tabuleiro de xadrez e que duplicava a quantia por cada quadrado que avançava.

Exponencial...

A escuridão tombava de todos os lados: uma esfera cantante, negra, uma pressão nos nervos de cristal, estirados, daquele universo de dados em que ele quase se transformara..

E então, quando já não era coisa alguma, comprimido no coração de todo aquele negrume, chegou uma altura em que a escuridão já não podia ser mais e qualquer coisa se despedaçou.

O programa Kuang jorrou da nuvem manchada e a consciência de Case fragmentou-se como gotas de mercúrio, que descreviam um arco elétrico por sobre uma praia sem fim, da cor escura das nuvens prateadas. A sua visão era esférica, como se uma única retina revestisse a superfície interior de um globo que contivesse todas as coisas, se todas as coisas pudessem ser contadas.

E aí todas as coisas podiam ser contadas, uma a uma. Sabia o número de grãos de areia no constructo da praia (um número codificado num sistema matemático que so existia na mente que era Neuromante). ${ }^{31}$

Gibson parece lançar seus cartógrafos/replicantes, dentro de um espaço dado explicitamente como cyber, ao buraco negro das possibilidades de uma outra cifragem, outra matemática (e também outra arquitetura) do universo.

31. G1BSON, Neuromancer. p. 285-286.
O que se dá na ordem de uma leitura/reescrita (que alcança o escritor americano, desde Poe, e o latino-americano, com o rastro também enorme de uma influência sobre a literatura européia, caso de Borges) do cosmológico e do cosmogônico. Em Neuromancer, a narrativa procede por linhas de ação popularizadas pelos media, e também de uma traição - tal como conceitua o filosofo e crítico da literatura em inglês - com respeito a uma ordem primeira, instância do controle, da razão no império cibertrônico (uma pirataria de dados, um deslocamento de contexto, de espaço, nos moldes da música eletrônica e do narrativo para Kathy Acker). Traição/tráfico de dados, que implica em uma radicalização do poético - e de uma poética - na esfera tecno, viabilizada, informatizada, por Gibson.

A narrativa como linha de fuga não se projeta como viagem no espaço superpovoado de signos antecipatórios, e emancipatórios, tal como ocorre nos quadrantes do sideral para a ficção-científica, mas como "aquisição de uma clandestinidade" - aquela obtida no cyberspace por Gibson e pelo narrador de Auster na passagem entre casas-cômodos e avenidas-alfabetos-números tão típicos da topografia, do mapa-anotação, de Manhattan - "Ser enfim desconhecido, como poucas pessoas o são, é isso, trair. É muito difícil não ser conhecido de todo, mesmo do porteiro do prédio, ou em seu quarteirão, o cantor sem nome, o ritornello (...) Como ultrapassar o muro, evitando de bater nele, de ficar atrás, ou de sermos massacrados? Como sair do buraco negro, em lugar de rodopiar lá no fundo, que partículas fazer sair do buraco negro?"32

Interessado nas pesquisas, na escrita de Burroughs, o filosofo de Mille plateaux encontra aí elementos para a formulação do cérebro como gráfico de ramificações/ rizomas, próprios a conexões e cognições, o cérebro como dispositivo cartográfico, capaz de armazenar dados e rasgos incessantes de combinações (velozmente operados pela memoria, da forma como leu Bergson), que a metáfora, tornada popular, do cérebro eletrônico acaba por consolidar. 0 cérebro, considerado como referência axial do humanismo, do racionalismo ocidental, submete-se, por obra de um filósofo guiado pela investigação às artes - e, no caso presente, a literatura americana, envolvida, desde Poe, com a ciência, com o constructo da narração - a uma virtualização a um só tempo técnica e tomada das forças mais contingentes, dos dados do corpo, dos percursos terrestres, que o tornam um verdadeiro spatium neuronal, alinhado ao traço descorporificante - corpo sem 6rgãos - das redes/linhas telemáticas, dos circuitos - cristais do espaço-tempo - "coexistentes mais ou menos extensos, sobre os quais se distribuem e correm as imagens virtuais." ${ }^{\text {"33 }}$

\section{DELEUZE, 1977, p. 57}

33. DELEUZE, "0 atual 8 o virtual". p. 49.

\section{REVISTA DE ESTUDOS DE LITERATURA \\ 8elo Horizonte y. $5,0.125-144$, out 97}


O que passa? O que se move? O que aconteceu? Que partículas se irradiam no proliferante espaço aberto do olho à tela líquida, no tabuleiro noturno de estrelas e supernovas? Que "caminhos de rato" são pespontados através do irromper bruto da erva sobre a terra? Essa resposta o filósofo francês pensa encontrar na produção literária, em língua inglesa - na narrativa americana, como aqui foi abordada - , de maneiras diversas, de formas transversas, que se reportam a um modo de cartografar o sistema de influências entre artes e nacionalidades, promissor à pesquisa, no qual desponta a aplicação do conceito filosófico, tão inventivo, e "cheio de força crítica, política e de liberdade"34 quanto o campo artístico, entendido que é por Deleuze como sistema aberto não mais relacionado a essências mas a circunstâncias.

Seu pensamento sobre o caso específico da literatura anglo-americana acaba, assim, por tornar atual, e intervencional, por força de sua estatura estratégica e cartográfica, a escrita narrativa, ao fim - em um tempo próprio a posteridades da idéia de literatura. Fornece, assim, elementos para um estudo operacional a ser realizado por ramificações proliferantes entre os saberes, entre as fronteiras, através de ramos perfurantes dos blocos econômicos dados hoje como nações, como versão do mundo/mapa da mundialização do capital (e as consequentes apropriações, segmentações do ganho, com linhas abertas de desterro/despovoação).

Não seria difícil encontrar na Inglaterra de Ballard, Amis, Rushdie, Kureishi, McEwan, Will Self, traços narrativos desta literatura de desbravação (não-modelar), na qual se notam novos acentos narrativos à altura de novas inserções no mercado, assim como na cena cultural, entendida em sua plena dimensão mediática, caso do escândalo religioso provocado por Rushdie, do contrato extraordinariamente alto de Amis, um anti-produtor de best-sellers, para escrever The information, em 1995. É o caso também do cinema trabalhado por Kureishi como roteirista - um dos mais importantes, dentro e fora do domínio inglês, como demonstra My beautiful laundrette (1986), dirigido por Stephen Frears - e realizador (London Kills me), assim como pela ligação com a vertente pop de boa parte da literatura atual, como ilustra The black album (1996), no qual tematiza a explosão representada pelo disco clássicofunk - que dá título ao livro - de Prince, quando se assinava com este nome, e o impacto de Versos satânicos contra os milenares mulçumanos.

A produção de Kureishi, filho de um paquistanês e de uma inglesa, parece adequar-se à perfeição ao termo multiculturalismo solto pelas bocas, solto no ar. Antes, porém, de atá-la a tal griffe terminológica, ou mesmo de inseri-la no quadro

34. DELEUZE, Conversarodes. P. 45 de uma expressão minoritária — o que certamente não induz ao conceito de literatura menor pensado por Deleuze -, torna-se inevitável sondar a complexa formação de um escritor mais próximo da sobreadolescência de uma cidade musical e comportamental como Londres, com todos os circuitos criativos, nervosos e noturnos de um universo de hibridização, do que como porta-voz homo-erótico e étnico.

Minorizar o legado inglês, retraçá-lo na subúrbia, sem que se constitua em um território acabado, entendido como mero receptáculo do exemplar e do estrangeiro. The Queen and her Princess are dead. Londres é enfocado no subúrbio do Ocidente/Oriente, no rosto e no corpo dos novos criadores (desde os punks, para tratar dos anos 70 para cá), um centro de arte, música e comportamento, tanto mais influente quanto mais descêntrico. $O$ mapa da literatura se recorta, $e$ seus agentes/autores são identificados a contar de seus atos de partida e da apropriação dos pólos dicotômicos centro-periferia.

Autores como Kureishi, lidos ao lado de Acker, Lish, Auster, Gibson, Pynchon e Burroughs (de quem Deleuze esteve próximo em momentos variados de sua filosofia), talvez venham apontar para o novo gregarismo, para o neotribalismo, de uma ficção pensada em termos de territorialidade, do trânsito indiscriminado de povos e alianças por vir. Não é por acaso que os elementos configurados como típicos de sociedades tão estratificadas, tão consolidadas, como essas do domínio anglo-americano, se deixam tomar pela tematização da orfandade (em Acker e Lish, McEwan). Com isso, mostra-se visível o projeto de reinvenção da infância, da origem, do corpo, enfim, como constituidor de um novo pacto de comunhão e de comunidade - um novo corpo amoroso (tal como articula a poética, inquietantemente atual, de Rimbaud), coordenado com as forças do cosmo e da terra, no interior de uma cultura marcada pelos rastros cada vez mais rápidos, mais e mais visíveis, dos passantes urbanos, dos migrantes de todos os lugares, assim como pela pulsação tecnológica, imaterial, do tempo.

O vórtice desterritorializante poderia ser direcionado até a nossa outra América, de modo a tornar mais pronunciados os escritos mapeadores de brasileiros como João Gilberto Noll, Raduan Nassar, Sergio Sant'Anna, Moacyr Scliar, Marilene Felinto, Zulmira R. Tavares, Vicente Cecim, Cristóvão Tezza, Bernardo Carvalho, tomando-se aí uma trilha teórica que atende ao dimensionamento de uma despovoação dos espaços, própria da reconfiguração do mapa terrestre, sinalizado por migrações, derrocadas imperiais de religiões e ideologias, guerras internas, invasões de sem-terra, por eclosões de minorias/ micronacionalidades de Ocidente a Oriente, em um processo descontínuo de redefinições geopolíticas (no qual se inclui o país-continente Brasil). De modo

REVISTA DE ESTUDOS DE LITERATURA
Belo Horizonte, v. 5, p. $125-144$, out. 97 
a ser possível sobre esse solo a literatura, que não abdica da pesquisa e da invenção, quer no terreno dos imateriais - que a cyber fiction apenas anuncia, com seu nome taxativo, sem limitar o valor e a criação de Gibson, Sterling e de um pioneiro como John Shirley - quer naquele dos passos concretos, traçados sobre a simultaneidade dos lugares, nacionais e nocionais. Daí (de onde) se engendra a busca (ante a mundialização da noção de mundo), sem demarcações, a despeito de todas as mediações/mediatizações, como potência conceitual e estética de um lançar-se ao canto e à ação da terra.

\section{ABSTRACT:}

This essay analyses some American and English contemporary authors from the point of view of Deleuze's concepts about the "superiority of anglo-american literature. KEY WORDS:

Narrative, Territoriality, Writing and Concept

\section{REEERENCIAS BIBLOGRRAFICAS:}

ACKER, Kothy. "Devoured by myths", on interview with Sylvère Lotringer". In: . Hannibal Lecter, My Fother. Novo York Semiatext (e), 1001. p. 1-24. My mother: Demonology. Nova York Grove Press, 1993.

ALILE, Eric. Do impossibilidode do fenomenologia. Sabre o filosofio frenceso contemporôneo. Irod. Roquel de Almeido Proda e Bento Prodo It. Säo Paulo. Ed. 34, 1996

AUSTER, Poul. A trilogia de Nova York. Trud. Morcelo Dios Almodo. São Paula, Bessseller, s/d.

BACHEĹARD, Goston. Rimboud l'enfont. In:__. 0 dinetio de sonhor. Trod. José Américo Pessontho et olii. Söo Paulo: Difel, 1986. p. 120-125.

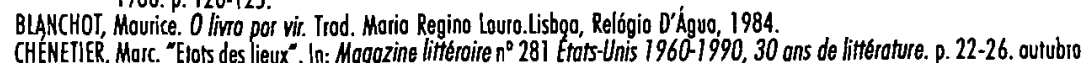
CHENETIER, Marc. "Elors des lieux". In: Magozine litterroire $n^{\circ} 281$ Etats-Unis 1960-1990, 30 ans de litterature. p. 22-26. outubro DELEUZE Gilles.

1977. "De lo superiont

1977.

e GuATtaRl. Qu'estire que lo philosophie? Poris, Minuit, 1991.

e GUATTARI, Felix. Mil platos. Yol. 1. Coord. de trod. Ano Lucio de Oliveiro. Rio de Joneiro, Ed. 34, 1995

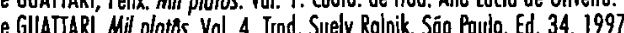

Critique et clinique. Paris. Minuit 1993

"O otual e o vintuol". In: AllleZ, Eric. Delevze filosofio viruol. Irad. Heloiso B. S. Rocha. Sõo Poulo, Ed. 34, 1996. p. 47

- 57

GIBSON, Williom. Neuromonte. Trod. Fernondo Correio Morques. Lisbao, Grodiva, 1988.

"Science fiction". In: Mondo 2000. A users guide to the new edge. (orgrg, Rudy Rucker et alii). Novo York, HorperPerenniol, 1992. p. 68-70.

GILBERT-ROLFE, Jeremy e JOHNSTON, John. "Grovity's Roinbow ond the Spiral Jetry". In: October, $n^{\circ} \mathrm{I}$, primovero 1976, p. 6585 .

KUREESHI, Honif. O buda do subúrbio. Trad. Celso Hogueiro. Söo Poulo, Componhio dos Letros, 1992

LISH, Gordon. Peru. Trod. Duda Mochado. Rio, Imogog, 1992.

PYNCHON, Thomos. Grovity's Roinbow. Hovo York, Viking, 1973.

ROSS, Kristin. "The right of loziness". In: L. The emergence of sociol space. Rimboud ond the Poris Commune. Minneopolis, University of Minnesoto Press, T988. p. 47-74.

\section{A CASA DESABITADA:}

\section{A NARRATIVA NO FIM DO MILÊNIO}

\author{
Myriam Ávila \\ UFMG
}

"A casa inteira parecia abandonada; as plantas do corredor e as poucas flores de inverno pareciam

clamar por contemplação."

Handke, A tarde de um escritor.

\begin{abstract}
RESUMO:
Este artigo apresenta a casa como imagem fundadora da narrativa e a cidade como imagem fundadora da narrativa moderna. Com a crise da modernidade, essas duas imagens arquetipicas se enfraquecem e passam a ser representadas na narrativa contemporanea como o lugar da falta e da perda, ou como simulacro. A novela A tarde de um escritor, perda, ou como simulacro. A novela A tarde de tratamento dado à casa e à cidade na narrativa do fim do milênio.

PALAVRAS-CHAVE:
\end{abstract}

Narrativa contemporanea, Peter Handke, Forrest Gump.

Convidada a dar um depoimento sobre a escrita', Marguerite Duras põe-se imediatamente a falar de sua casa. $\mathrm{O}$ quarto, "aquele de armários azuis, hoje, que pena, destruídos por jovens pedreiros", uma certa janela, uma certa

1. 0 depoimento, feito o princípio poro um documentório filmodo no coso do escritoro, oporece depois como reloto escrito en DURAS, 1993. 